Revista Iberoamericana, Vol. LXX, Núm. 206, Enero-Marzo 2004, 275-283

\title{
LA CASA Y LA DOMESTICIDAD COMO METÁFORAS DE LA OPRESIÓN SOCIAL: EL TESTIMONIO DE DOMITILA BARRIOS
}

\author{
POR \\ María Elva Echenique \\ Universidad de Oregon
}

Domitila Barrios, la mujer minera boliviana, es recordada sobre todo por su controversial intervención en el Foro Internacional de la mujer realizado en México el año 1975. En el evento, Barrios tomó la palabra -sin que se la concedieran- para expresar su visión sobre la problemática de la mujer latinoamericana de clase trabajadora que, desde su perspectiva, estaba siendo ignorada. Su discurso enfatizó las diferencias irreconciliables que separan a las mujeres de diferente clase social en América Latina impidiendo una identificación entre ellas y, de esta manera, provocó el cuestionamiento del concepto esencialista de “mujer” manejado en la agenda feminista del congreso. La intervención de Barrios, no sólo puso de manifiesto los límites de representación del sujeto de una corriente feminista universalizante que dominaba la época, sino que evidenció claramente la imposibilidad de aproximarse a la cuestión de género, sin tomar en cuenta otras variables como las de clase, o etnia, con las que está inextricablemente ligada.

Poco tiempo después, como resultado de su participación en el encuentro de mujeres y motivada por la urgencia política de denunciar las violaciones a los derechos humanos que ocurrían en su país, Barrios publicó, en colaboración con la antropóloga Moema Viezzer, un testimonio sobre su vida como mujer de clase trabajadora y dirigente de una organización de mujeres en un campamento minero de Bolivia. El título del testimonio, Si me permiten hablar, evoca la anécdota de la intervención a la que nos referimos antes y en él Barrios se propone describir las condiciones de vida y las luchas de la clase minera Boliviana, así como denunciar la represión que varios gobiernos autoritarios ejercen sobre ella. En su relato, Barrios prosigue el diálogo iniciado con las mujeres asistentes al Foro de México y expresa su convencimiento sobre la centralidad del factor de clase en la determinación de la condición de vida de la mujer trabajadora, desestimando la cuestión de género y expresando su rechazo del feminismo al que considera "un arma más del imperialismo".

En este trabajo nos proponemos analizar la estrategia discursiva utilizada por Barrios en su narración. Postulamos que, al privilegiar el espacio doméstico como sitio desde el cual enuncia su narración, Barrios se ubica en un lugar estratégico en el que se intersectan variables de clase y género. Desde esta posición, su discurso consigue articular su visión de la opresión de la clase minera boliviana y la de la condición de la mujer de clase trabajadora, denunciando de esta manera, no sólo la violencia ejercida sobre la comunidad 
minera, sino también la violencia a que están sometidas las mujeres de clase trabajadora en una cultura patriarcal machista.

El espacio doméstico ocupa un lugar preponderante en la narración de Barrios como consecuencia de su experiencia personal. Barrios es madre de siete hijos en una familia minera y dirigente de una organización de mujeres surgida de la urgencia de luchar por las necesidades básicas de las familias en los campamentos mineros. En su relato, sin embargo, el espacio doméstico, representado por la pobre vivienda que habita la familia minera, no aparece sólo como el escenario de fondo en el que se desenvuelve su vida, si no que se convierte en metáfora, por la elección consciente que hace la narradora de contar su historia desde allí. En su discurso, la casa es usada como un prisma a través del cual se contemplan otros espacios. Nuestro análisis intenta mostrar cómo, a través de la metáfora de la casa-con todas las oposiciones que evoca: público/privado, dentro/fuera, interioridad/ exterioridad- Barrios denuncia la opresión en que viven los trabajadores mineros y paralelamente también la opresión a que están sometidas las mujeres. En su testimonio, la casa -símbolo universal de la domesticidad- adquiere una connotación negativa al servir de prisma a través del cual se iluminan otros espacios opresivos.

La casa como espacio físico concreto en el que se desenvuelve la vida de la familia y en torno al cual se organiza la experiencia vital de la mujer en la sociedad patriarcal, es por antonomasia el lugar privilegiado de la vida privada, de la cotidianidad. Es en torno a este espacio que se construye la identidad genérica de la mujer, y es alli donde se concentra la mayoría de sus actividades de acuerdo a la división sexual tradicional del trabajo. Puede afirmarse por tanto que, al interior de la ideología patriarcal burguesa, la esencia de la feminidad está inextricablemente ligada al espacio de la casa. En este sentido, la ideología de la feminidad burguesa que confina a la mujer al espacio privado se reproduce a través de un culto de la domesticidad que exalta las labores derivadas de la maternidad femenina, naturalizándolas y otorgándoles un valor social postivo.

La utilización de la casa como metáfora de la opresión, reviste especial interés si se considera a la luz de estudios recientes desde la teoría feminista que cuestionan la organización política y cultural de la casa desde el punto de vista de su arquitectura. En su libro, Gendered Spaces, Daphne Spain analiza el espacio de la casa como parte constitutiva de la institución familiar. Desde su perspectiva, la dimensión espacial de las instituciones cumple una función esencial en la reproducción de la jerarquía de género al asignar diferentes espacios a hombres y mujeres, adscribiendo mayor valor al espacio público productivo masculino que al espacio privado de la reproducción femenino. Spain afirma que la espacialización de las instituciones contribuye a formar una barrera que impide que las mujeres adquieran el conocimiento necesario para alterar las relaciones de poder. En este contexto, el espacio doméstico, considerado universalmente como femenino en la sociedad patriarcal, se constituye en un factor importante en la reproducción de la subordinación femenina. Desde otro ángulo, Mark Wigley, en su artículo “The Housing of Gender” estudia los mecanismos a través de los cuales la casa contribuye a la reproducción de "la ley del padre”. Su estudio revela la violencia sobre la cual se construye el régimen doméstico, es decir, la domesticación de la mujer y el control de su sexualidad, que tienen por objeto proteger los derechos genealógicos del padre. Los trabajos de Spain 
y Wigley contribuyen a la desmitificación de la institución familiar y del culto de la domesticidad propios de la ideología patriarcal burguesa. Desde esta perspectiva, al metaforizar la realidad de marginación del minero así como la violencia del Estado represivo a través de imágenes relacionadas con la casa, el texto de Barrios contribuye también a la desconstrucción de la ideología burguesa de la domesticidad. En el texto de Barrios, la violencia que implica la domesticación de la mujer en el espacio de la casa, se desplaza al cuerpo social para revelar la violencia estatal ejercida sobre las clases subalternas, en un proceso de domesticación de los cuerpos que permite reproducir el sistema de explotación.

El testimonio de Barrios se inicia con una descripción amplia del país -la gran casa-, continúa con una descripción del campamento minero -la casa de la mina-, y culmina con la descripción de la casa en que habita Barrios, desde la que narra su historia. Esta reducción progresiva del espacio hasta llegar al sitio de donde proviene la voz de la narradora produce un efecto significativo: por una parte, el de acercar al lector al mundo doméstico, femenino, en el que se desarrolla la actividad cotidiana de la mujer y de la familia; por otra, el de establecer la condición de clase y el nivel económico de la mujer que habla:

Nuestra vivienda es muy reducida, o sea que es un cuartito de cinco o seis metros. Ese cuartito tiene que ser sala, comedor, despensa, dormitorio. En mi caso, armamos tres camas en el cuarto, es todo lo que entra. Aquí duermen mis siete hijos, aquí hacen los chicos sus tareas, aquí comemos, aquí juegan los chiquitos... (22)

Es desde este espacio pequeño, pobre, de hacinamiento, despojado de toda comodidad, desde el que nos llega la voz de Domitila Barrios. Ella habita "la casa de una sola pieza”, por tanto, diferente de la casa "moderna” que habita la mujer de la clase dominante. Marcia Stephenson, en su artículo "Hacia un análisis de la relación arquitectónica entre el género femenino y la raza en Bolivia” analiza el modelo de casa predominante en el país:

La representación predominante de la casa moderna en Bolivia es una que organiza los espacios públicos y privados para enfatizar una lógica criolla basada en conceptos dominantes como la propia propiedad, el individualismo, lo privado. (61)

Es decir, que la "casa hegemónica" es aquella que permite reproducir los valores de la modernidad burguesa, entre ellos, los de la ideología de la feminidad a que hicimos referencia. En Bolivia, la casa hegemónica es habitada por la mujer de la élite dominante, de ascendencia blanca o criolla. Stephenson añade que:

Las denominadas casas “normativas” y por tanto hegemónicas, domestican tanto cuerpos individuales como familias conduciéndoles a la fuerza, al ámbito de lo familiar; en otras palabras, el funcionamiento de las casas hegemónicas construye procesos de afiliación étnica y racial al tiempo que organiza las construcciones dominantes de género. (61)

En este sentido, en Bolivia, la “Casa normativa” no sólo refuerza los roles genéricos tradicionales, sino que también posibilita la estratificación étnica y de clase de sus 
ocupantes, por medio de la creación de espacios reservados sólo a los dueños o a la servidumbre y la delimitación de fronteras al interior de la misma. Al no ajustarse a las especificaciones de la casa moderna, la casa descrita por Barrios enfatiza las diferencias de clase y socioeconómicas y las distancias que existen entre las mujeres, como ocurre cuando, al dirigirse a una de las representantes mexicanas en el encuentro de mujeres, Barrios expresa: "Estoy segura de que usted vive en una vivienda bien elegante, en un barrio también elegante, no? Y, sin embargo, nosotras las mujeres de los mineros tenemos solamente una pequeña vivienda prestada” (223).

La enunciante del relato se sitúa, entonces, desde el principio en un espacio femenino, marcado por el signo de la pobreza. Barrios no es solamente una representante de la comunidad minera, lo es desde su condición genérica de “ama de casa”. Su experiencia vital está marcada por las tareas que tradicionalmente se esperan de ella como esposa y madre, en el ámbito de la casa, donde como hemos visto, la mujer se define en subordinación a la ley del padre. Es desde allí que ella relata la historia de la opresión de su gente. Su interpretación de la historia no puede desligarse de su condición de género.

Al empezar el relato, Barrios caracteriza la situación de desposeimiento del minero refiriéndose a la casa: “A pesar de que los mineros vivimos como gitanos en nuestra propia tierra, porque no tenemos casa, solamente una vivienda prestada por la empresa durante el tiempo en el que el trabajador es activo” (18). Barrios recurre con insistencia al tópico de la casa prestada. La carencia de una vivienda propia no sólo enfatiza la pobreza en la que vive el minero, sino que describe la situación precaria de la clase trabajadora en una nación con un sistema de producción capitalista, donde los trabajadores de las minas son sólo "inquilinos" en una casa que no les pertenece. Esta conciencia de ser desposeídos se agudiza cuando Barrios narra la forma en que las familias de los mineros son echadas de la casa al dejar éstos de pertenecer a la empresa, y sobre todo cuando relata su propia experiencia de desalojo:

Finalmente, hablé fuerte a mis hijos: -nos están botando los dueños. Nosotros somos pobres, y a los pobres los botan así, la casa no es nuestra... Dicen que la tierra es para quien la trabaja. Aquella tierra de la mina que han trabajado nuestros padres era lo único que teníamos. Y sin embargo, nos tuvieron que arrojar de allí. Eramos extraños en nuestro propio país. (152)

Al igual que la casa de la mina en la que los mineros son inquilinos temporales, la tierra boliviana tampoco le pertenece a la clase trabajadora. En la casa boliviana, de propiedad de una élite burguesa, al minero le pertenece sólo el espacio de la servidumbre, espacio precario que lo sitúa en la marginalidad, como ciudadano de segunda clase.

Desde la perspectiva de su ideología de izquierda, Barrios concibe al país como una gran casa que ha sido expropiada por los explotadores vinculados a intereses extranjeros y en la que los verdaderos dueños, los que trabajan la tierra, han sido despojados y viven en condiciones de extrema miseria, como "gitanos” o “extraños” en su propio país: “Aparentemente, el pueblo boliviano es dueño de estas riquezas... pero, esa riqueza no nos pertenece. Y en realidad es porque Bolivia se halla sometida a las empresas transnacionales” (18). 
El desposeimiento y la marginalidad de la clase trabajadora se hacen evidentes en la narración de Barrios a través de la descripción de la precariedad del espacio reservado a la familia. Más aún, las anécdotas referidas al desalojo de la familia cuando el minero muere o es despedido, apuntan a la extrema dependencia económica de la mujer dentro de la cultura minera. El hecho de que toda la actividad de los campamentos mineros, aislados en sitios remotos, gire en torno a la mina, resulta en perjuicio de las mujeres y contribuye a su extrema subordinación. El espacio de la mina, resguardado por mitos que prohiben el ingreso de la mujer a los socavones, es un espacio exclusivamente masculino, lo que impide la incorporación de la mujer a la fuerza de trabajo productivo remunerado. En estas circunstancias, la división de los roles tradicionales de género y la subvaloración del trabajo doméstico no remunerado, se ven acentuadas y reforzadas por una ideología que explica el confinamiento de la mujer al espacio doméstico sobre la base de su inhabilidad física e intelectual natural. La infravaloración de la mujer dentro de la clase minera aparece ejemplificada en el relato de Barrios cuando recuerda la orfandad de su infancia: “cuando murió mi mamá, la gente nos miraba y nos decía: ‘Ay! pobrecitas, cinco mujeres ningún varón... para qué sirven, mejor si se mueren’” (59). La casa precaria o prestada connota entonces la marginación de la clase minera y, al mismo tiempo, la doble marginación de la mujer de clase trabajadora: la marginación de género dentro de su propia clase.

Las humillantes condiciones laborales en las que trabaja el minero son contempladas por Barrios también desde la casa. En su relato, ella menciona sólo de manera general las precarias condiciones en las que los mineros trabajan en la mina, especialmente en el interior. Sin embargo, al dotar a la casa del minero de características similares a aquellas del socavón, Barrios extiende el espacio de opresión laboral también al ámbito privado de la vida del minero:

Nuestra vivienda es un cuartito de cuatro por cinco o seis metros. En esto consiste la vivienda que nos presta la empresa, pero solamente las cuatro paredes sin ningún servicio de agua o instalación sanitaria. Y así tenemos que vivir con más nuestros hijos en una gran estrechez. (22)

Por cierto, la casa no sólo se parece al socavón por ser un espacio pequeño, estrecho, despojado de cualquier servicio. La atmósfera opresiva de la mina también se traslada a la casa, que es oscura, peligrosa, y que no ofrece protección real a la familia:

Echaba llave a la casa y tenían que quedarse las wawas en la calle, porque la vivienda era oscura, no tenía ventana, y les daba mucho terror cuando se las cerraba, era como una cárcel, solamente con una puerta. (56)

Como los socavones de la mina, sumidos en la oscuridad y sin ventilación, que no ofrecen a los mineros las más mínimas condiciones para un trabajo digno, así también la casa no las ofrece para que la mujer desarrolle su trabajo doméstico:

La vivienda es pésima, el agua solamente la tenemos en piletas públicas, los baños son colectivos, la energía eléctrica la tenemos las horas que nos da la empresa... (61) 
En estas condiciones, el trabajo doméstico de la mujer se multiplica también hasta adquirir las mismas características de excesiva explotación en las que trabaja el hombre en la mina:

Ellas (las mujeres asistentes al Foro de México) no sabían como nosotras, lo que es levantarse a las 4 de la mañana y acostarse a las once o doce de la noche solamente para dar cuenta del quehacer doméstico, debido a la falta de condiciones que tenemos nosotras. (226)

Barrios hace sólo una alusión muy breve al trabajo dentro de la mina. Sin embargo, las condiciones inhumanas en que debe trabajar el minero son enfatizadas a través de la metáfora que asocia la estrecha vivienda del minero con un socavón: El espacio opresivo, oscuro y sin protección de la mina es también el que gobierna la casa y en ella la mujer está también sometida a la excesiva explotación. La domesticidad adquiere a través de esta metáfora contornos desoladores, los de la lucha por la supervivencia en medio de la miseria, que hacen del trabajo de la mujer una labor agobiante y penosa. La noción burguesa del hogar como ámbito cerrado y protegido, de signo positivo, se ve cuestionada a través de la descripción del espacio físico absolutamente precario que ocupa la familia minera y de la descripción del trabajo agobiante que deben realizar no sólo la mujer si no también los hijos de la familia de clase trabajadora.

A la opresión económica y laboral, se suma la opresión política, opresión que se expresa a través de la represión militar ejercida en los centros mineros. Es ésta quizá la que se describe con más dramatismo desde "la casa”. Para Barrios, la casa es a veces también una cárcel, especialmente en épocas de alta represión: “Cada noche tenías un soldado en tu puerta. En todas las viviendas del campamento era así. Por eso digo: era zona militar... peor que en un campo de concentración hemos estado en el siglo xx en ese tiempo” (106). La pequeña vivienda convertida en cárcel por la presencia de los militares que la vigilan refuerza la percepción del espacio doméstico como un espacio opresivo, vigilado, susceptible de ser invadido. La casa se constituye en un encierro para sus habitantes privados de libertad. Así, el abuso del poder y la violencia de los militares son relatados por Barrios en anécdotas relacionadas con la casa. Se trata de invasiones, allanamientos de las humildes casas de los mineros a través de las cuales denuncia la violación del ámbito privado reservado a la familia, y que prefiguran la violación del ámbito más íntimo del ser humano: su cuerpo, a través de la tortura.

Al rememorar los allanamientos, Barrios incluye detalles dramáticos relacionados con el abuso de niños, mujeres, hombres enfermos o discapacitados. "En otra casa, lo propio. Estaba cerrada y tocaron la puerta. La señora estaba yendo a abrir y... !pa!...!pa!, le tiraron, y allí mismo se murió” (107). El episodio histórico de la masacre de San Juan, por ejemplo, es narrado desde la perspectiva del sufrimiento de víctimas inocentes. Barrios centra su relato en anécdotas privadas, “marginales” en relación al hecho histórico central constituído por el enfrentamiento entre militares y mineros. Desde esta perspectiva, la masacre adquiere otros contornos, en ella se ven representadas las víctimas más débiles y el abuso de la violencia se ve exacerbado. 
A la casa que se convierte en cárcel se contrapone la cárcel que se convierte en casa. En su primer apresamiento Barrios lleva consigo a su niña de dos años, la misma que comparte su cautiverio. La presencia de la niña junto a su madre convierte la cárcel en casa. Con la presencia de la niña, el espacio privado del hogar se traslada a este recinto, que no sólo cobija un individuo que esta fuera de “la ley” sino a una familia. La huelga de hambre que Barrios inicia en su celda junto a su hija, provoca indignación en la ciudadanía que se solidariza con ella. La cárcel convertida en casa hace patente la dimensión privada del conflicto de los mineros. La población urbana reacciona cuando la cotidianeidad de la vida privada, cuyo espacio es el hogar, se traslada al espacio público de la cárcel, personalizando el conflicto social. La niña se convierte en un arma de negociación, en posibilidad de libertad para Barrios.

Perseguida y encarcelada más de una vez por su actividad política en su posición de dirigente del Comité de Amas de Casa, organización de mujeres que respalda la lucha de los trabajadores mineros por mejores condiciones de vida, Barrios narra en su testimonio su apresamiento y tortura cuando se la acusa de estar relacionada con el movimiento guerrillero que operó en el país a fines de la década del sesenta. Su narración de esta experiencia exacerba el cuadro de opresión y violencia relacionado con el ámbito doméstico al recaer la tortura sobre un cuerpo femenino, un cuerpo que además es también casa, al albergar a un niño en su seno. En la visión patriarcal, la casa como ámbito cerrado, incontaminado en el que se origina y desarrolla la vida del ser humano en una atmósfera protegida y segura, remite a la idea de la madre, del origen. En este sentido, el útero de la mujer es también una casa, la casa-vientre. En el relato de Barrios, la casa más íntima del ser humano, el vientre materno, es también invadida y violada simbolizando así en grado máximo la violencia de la represión militar: "En un momento dado, me puso su rodilla aquí, sobre mi vientre, Me apretó mi cuello y estaba por ahorcarme. Yo gritaba... gritaba. Parecía que quería hacer reventar mi vientre...” (159).

Barrios, embarazada de ocho meses, aborta su niño a causa de la tortura. En su narración recuerda sus intentos desesperados por mantener al niño en su vientre: "Empecé a sentir dolores, dolores y dolores. Y a ratos ya me vencía la criatura para nacer y yo me la sujetaba ¡no quería que nazca...!” (163). En esta situación desesperada, ante la violencia inhumana de su torturador, Barrios opone resistencia. En este relato de su parto-aborto, una experiencia netamente femenina, se conjugan todas las opresiones. La imagen del niño desalojado del vientre de la madre sintetiza el horror de la violencia social al que ya nos acercara la narradora a través de la descripción de desalojos, allanamientos e invasiones del espacio privado de la casa. Es más, esta experiencia traumática relacionada con la maternidad desafía una vez más las nociones que asocian la maternidad a sentimientos de felicidad y plenitud, al hogar protegido en el que la madre es exaltada.

En el cuerpo femenino torturado se conectan todas las opresiones. A la violencia del Estado autoritario se suma la violencia contra la mujer en una sociedad machista expresada en boca del militar que tortura a Barrios. La cita siguiente subraya esta violencia de género:

Pero su principal objetivo era burlarse de mí. Y como vio que yo estaba esperando familia, me preguntaba si no sabía para qué servían las mujeres. Y para qué nos metíamos a macanas si la mujer estaba hecha solamente para dar placer al hombre. Y me insultaba, así no? (157) 
Al rememorar los insultos del torturador, Barrios enfatiza la doble rebeldía por la que debe ser castigada la mujer. No es sólo su actividad política enmarcada en la lucha de clases la que debe castigarse es, sobre todo, su transgresión de los roles de género impuestos por la ideología patriarcal. Al atreverse a traspasar el límite del encierro doméstico, participando activamente en la vida política de su comunidad, Barrios amenaza el orden patriarcal. Como lo vemos en la cita, es esta transgresión el objeto del interrogatorio.

En el testimonio, los representantes de la autoridad -policías que desalojan a la familia minera de la vivienda, soldados que custodian las puertas, militares y torturadorestienen en común el uso de la violencia, que no sólo se restringe al ámbito público si no, como hemos visto, invade también el ámbito privado de la vida. Más aún, la descripción de la autoridad masculina al interior de la familia, representada por padres o esposos de las mujeres mineras, refuerza la visión negativa de la masculinidad. La violencia de género expresada en el maltrato a la mujer dentro del hogar sale a la superficie repetidas veces en el relato de Barrios aunque ella no se proponga plantearla explícitamente. Se hace visible, por ejemplo, en un episodio en el que Barrios comenta la reacción de los hombres mineros frente a la actuación política de las mujeres:

Hay compañeras que sólo participan cuando algo muy especial ocurre. Por ejemplo, cuando convocamos a una manifestación para reclamar el aumento de cupo, en el 73, unas cinco mil mujeres participaron. $\mathrm{Y}$ cuando volvieron a sus casas, muchos trabajadores las pegaron y dijeron que ellas eran amas de casa y que no tenían nada que ver con política. (84)

Los episodios de violencia doméstica descritos en el contexto de un sistema de violencia mayor -la del Estado autoritario que ejerce represión sobre la clase trabajadorarefuerzan la doble denuncia de la narradora, creando un paralelismo entre el ámbito público y el privado. El abuso del poder adquiere similares características en el sistema social autoritario y en la familia patriarcal marcada por el machismo.

Al servir de prisma desde el que se iluminan otros espacios opresivos, la casa aparece en el discurso de Barrios como símbolo en el que se conjugan la opresión social y la de género. La casa de una sola pieza a través de la que se denuncia la opresión económica, laboral y política a que está sometida la clase minera, sirve también para denunciar la opresión de la mujer de clase trabajadora. Más aún, este espacio femenino, identificado con el cuerpo de la mujer en el episodio de tortura, aparece marcado por el signo de la violencia: violencia explícita en la represión política o en la violencia doméstica ejercida contra las clases subalternas y las mujeres, y violencia ideológica sobre la que se construyen, por una parte la sociedad autoritaria y por otra, el régimen doméstico. Con su estrategia narrativa, Barrios va más allá de su intención de denuncia del régimen autoritario, para hacer una crítica profunda de la sociedad patriarcal, y de la autoridad masculina sobre la que ésta se funda. 


\section{Bibliografía}

Barrios de Chungara, Domitila. Si me permiten hablar. México: Siglo XXI, 1978.

Cajías de la Vega, Magdalena e Iván Jiménez Chávez. Mujeres en las minas de Bolivia. Serie Protagonistas de la Historia. La Paz: Bolivia 2000 SRL, 1997.

Spain, Daphne. Gendered Spaces.Chapel Hill: University of North Carolina Press, 1992. Stephenson, Marcia. "Hacia un análisis de la relación arquitectónica entre el género femenino y la raza en Bolivia”. Escarmenar: Revista Boliviana de Estudios Culturales 2. La Paz: Plural, 1997.

Wigley, Mark. “The Housing of Gender”. Sexuality and Space. Princeton: University School of Architecture, 1992. 